\title{
Особенности процесса спекания макропористого кремния в атмосфере аргона
}

\author{
(C) Е.В. Астрова, Н.Е. Преображенский, С.И. Павлов, В.Б. Воронков \\ Физико-технический институт им. А.Ф. Иофрфе Российской академии наук, \\ 194021 Санкт-Петербург, Россия \\ E-mail: east@mail.ioffe.ru
}

(Получена 8 февраля 2017 г. Принята к печати 16 февраля 2017 г.)

Исследованы температурная и временна́я зависимости процесса спекания макропористого кремния в $\mathrm{Ar}$ и $\mathrm{Ar}+3 \% \mathrm{H}_{2}$. Определен вклад различных механизмов, определяющих этот процесс. Особенности спекания макропористого кремния изучались с помощью изохронных и изотермических отжигов на образцах с регулярными и случайными макропорами в диапазоне $1000-1225^{\circ} \mathrm{C}$. Установлено, что на спекание макропористого кремния при атмосферном давлении в потоке инертного газа, содержащего $2 \cdot 10^{-4} \% \mathrm{O}_{2}$, существенное влияние оказывает термическое травление. Термическое травление конкурирует с процессами переноса вещества, характерными для спекания, и препятствует формированию на поверхности бездефектной корки. Причиной травления является образование газообразной моноокиси кремния, которая уносится вместе с потоком газа. Эффект травления преобладает в области низких температур и не зависит от добавки водорода. Полученные значения энергии активации коэффициента диффузии $E_{a}=2.57$ эВ и показатель степени $n=3.31-3.74$ в зависимости радиуса пор от времени $r \sim t^{1 / n}$ свидетельствуют о смешанном механизме переноса вещества с помощью поверхностной и объемной диффузии атомов кремния.

DOI: 10.21883/FTP.2017.09.44885.8544

\section{1. Введение}

Инертный газ, даже высокой чистоты, содержит небольшое количество окислителя в виде кислорода или паров воды, которые оказывают заметное влияние на происходящие процессы реорганизации пористой структуры. Наиболее подробно сравнение отжигов в $\mathrm{H}_{2}$, проводившихся в реакторе для эпитаксиального наращивания, с отжигами в $\mathrm{Ar}$ в печи с горизонтальной трубой было проведено в работах $[1,2]$. Однако изучение спекания в этих работах проводилось с точки зрения возможности сформировать полость (SON-структуры) на большой площади и ограничивалось фиксированной температурой. Авторы пришли к выводу о том, что аргон можно использовать вместо водорода для получения SON-структур на образцах с регулярными макропорами, однако при этом поверхность пластин имеет значительно большее число дефектов.

Цель настоящей работы заключается в более детальном изучении процессов спекания макропористого кремния в среде инертного газа и выявлении его особенностей. В задачу входило проведение изохронных и изотермических отжигов, нахождение температурных и временны́х зависимостей среднего размера пор внутри пористого слоя и отверстий в поверхностной корке, а также анализа механизмов, определяющих трансформацию пористой структуры.

\section{2. Методика эксперимента}

Для проведения отжигов использовались макропористые слои, изготовленные с помощью электрохимического травления. Исходным материалом служили кремниевые пластины $p$-типа (100) с удельным сопротивлением 15 Ом · см. На поверхности образца SQ4-29 имелись затравки, организованные в квадратную решетку с периодом $a=4$ мкм, остальные образцы были без затравок. После анодирования в 4\% растворе НF в диметилформамиде при плотности тока $4 \mathrm{MA} / \mathrm{cm}^{2}$ в образце с затравками формировалась регулярная сетчатая структура, в образцах $p$-Si-4, $p$-Si-6 и $p$-Si-7 при плотности тока $15 \mathrm{~mA} / \mathrm{cm}^{2}-$ саморганизующаяся решетка случайных пор. Более подробно технология анодирования $p$-Si описана в работе [3]. Для проведения изохронных и изотермических отжигов образец с пористой областью диаметром 20 мм разрезался на 4-6 частей, и каждая часть отжигалась в своем режиме. Параметры пористой структуры и условия термообработки приведены в табл. 1 , где $a-$ среднее расстояние между порами, $l$ - глубина пор в исходной структуре после анодирования. Изохронные отжиги проводились в течение $t=30$ мин при разных температурах в диапазоне $1000-1200^{\circ} \mathrm{C}$ (отжиг 13-10) и в диапазоне $1100-1225^{\circ} \mathrm{C}$ (отжиг 19-10). Изотермический отжиг проводился при 1125 и $1225^{\circ} \mathrm{C}$, длительность отжига варьировалась от 12.5 до 420 мин. В остальном методика подготовки образцов для отжига, скорость газового потока, режим нагрева/охлаждения и приготовление сколов для последующего анализа были такими же, как и в работе [4].

Обработка изображений поверхности образцов с нерегулярной решеткой пор проводилась с помощью программы Image J [5]. Для подсчета плотности незакрывшихся поверхностных пор (отверстий в корке) $N$ и среднего значения их площади $S$ подбирались оптимальные методы сегментации полутоновых изображений с тем, чтобы регистрировать достаточно глубо- 


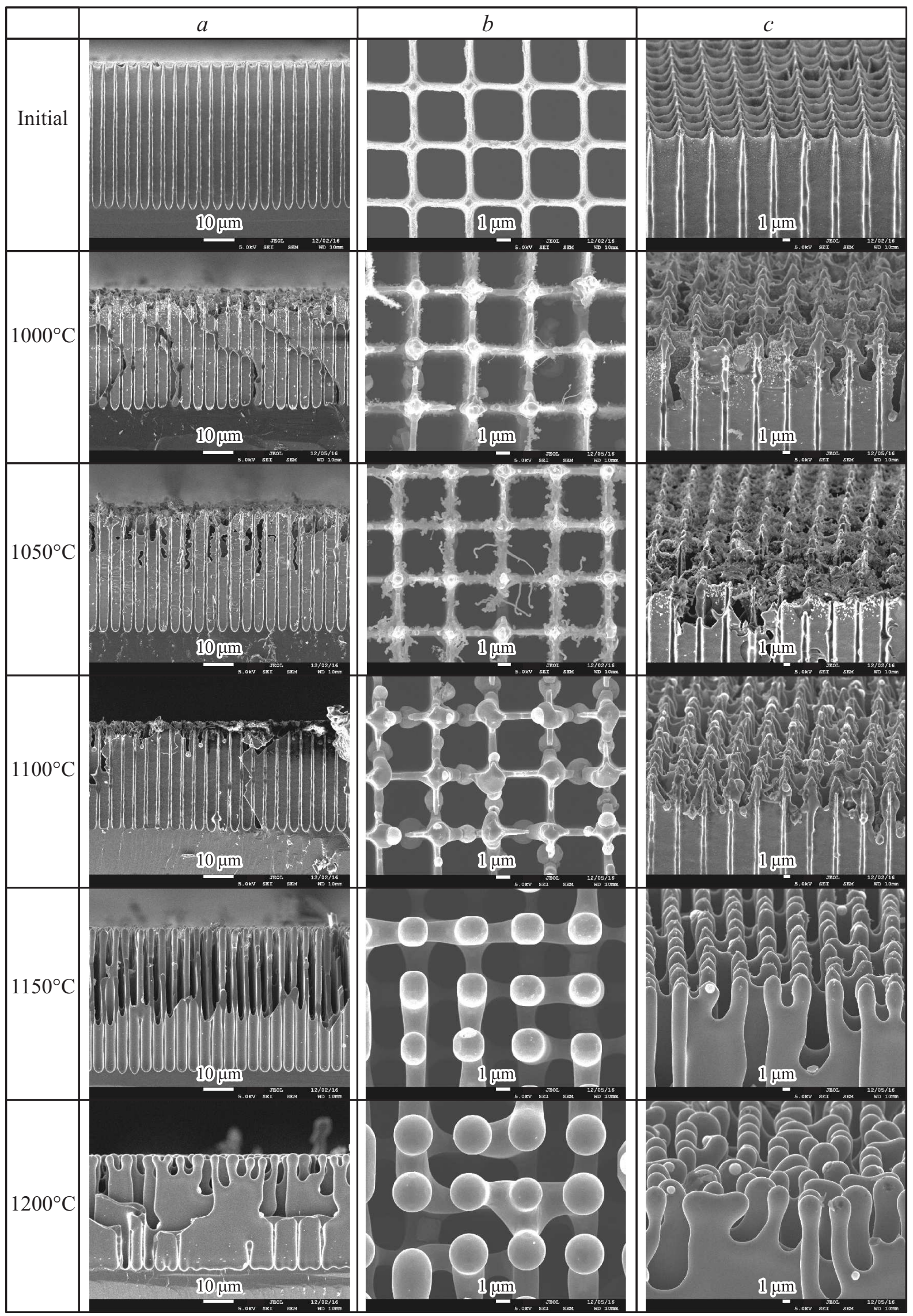

Pис. 1. Изохронный отжиг образца SO4-29. Масштабный отрезок: $a-10$ мкм, $b$ и $c-1$ мкм. 
Таблица 1. Параметры образцов и режимы отжига

\begin{tabular}{|c|c|c|c|c|c|c|}
\hline Отжиг & Образец & $a$, мкм & $l$, мкм & $T,{ }^{\circ} \mathrm{C}$ & $t$, мин & Атмосфера \\
\hline $\begin{array}{c}13-10 \\
\text { изохронный }\end{array}$ & SQ4-29 & 4.00 & 47.0 & $\begin{array}{c}1000,1050,1100 \\
1150,1200\end{array}$ & 30 & $\mathrm{Ar}$ \\
\hline $\begin{array}{c}19-10 \\
\text { изохронный }\end{array}$ & $p$-Si-4 & 1.95 & 35.5 & $\begin{array}{l}1100,1125,1150 \\
1175,1200,1225\end{array}$ & 30 & $\mathrm{Ar}$ \\
\hline $\begin{array}{c}28-10 \\
\text { изотермический }\end{array}$ & $p$-Si-6 & 1.95 & 48.6 & 1125 & $\begin{array}{c}12.5,30,60 \\
160,360\end{array}$ & $\mathrm{Ar}$ \\
\hline $\begin{array}{c}\text { 8-11 } \\
\text { изотермический }\end{array}$ & $p$-Si-7 & 1.95 & 46.0 & 1225 & $\begin{array}{c}12.5,30,60, \\
160,420\end{array}$ & $\mathrm{Ar}+\mathrm{H}_{2}$ \\
\hline
\end{tabular}

кие поверхностные полости, имеющие наиболее темный цвет, и обеспечить условия, при которых они с одной стороны не сливаются с соседями, а с другой - не дают потеряться малым порам. Учитывались только те незакрывшиеся поры, площадь которых была больше чем $10 \%$ от среднего значения $S$ в исследуемом образце. Средний радиус поверхностных отверстий определяли как $R=(S / \pi)^{1 / 2}$, полагая их форму круглой. Преобразования внутри пористого слоя оценивались путем измерения диаметра пор на изображении поперечного сечения в верхней его части под коркой и вычисления среднего радиуса $r$. По тем же изображениям определяли высоту пористого слоя $l$.

\section{3. Результаты и обсуждение}

\section{1. Изохронный отжиг}

На рис. 1 показаны результаты отжига образца SQ4-29 с упорядоченной решеткой пор при разной температуре. В левом столбце приводится изображение поперечного сечения, в среднем - вид сверху, а в правом изображение скола, полученное под углом $25^{\circ}$ к поверхности. Хорошо видно, что при температурах $1000-1100^{\circ} \mathrm{C}$ происходит травление поверхности и образование окисного покрытия в виде ваты или окисных шариков. Эффект собственно спекания начинается между 1100 и $1150^{\circ} \mathrm{C}$.

Поскольку исходная структура имеет высокую пористость, то при $1150^{\circ} \mathrm{C}$ происходит слияние пор и формирование в узлах решетки отдельно стоящих $\mathrm{Si}-\mathrm{c}$ солбиков с утолщением наверху. Процесс начинается с верхней части структуры. Утолщения на изображении сверху выглядят как квадратные головки с выраженной огранкой. При $1200^{\circ} \mathrm{C}$ эти утолщения увеличиваются в диаметре и приобретают сферическую форму. Спекание пористой структуры сопровождается уменьшением высоты пористого слоя $l$. В табл. 2 приведены значения высоты пористого слоя после отжига при каждой из температур.

Из таблицы видно, что вопреки возможным ожиданиям, наибольшее изменение $l$ соответствует $T=1100^{\circ} \mathrm{C}$. В диапазоне $1000-1100^{\circ} \mathrm{C}$ уменьшение высоты пористого слоя обусловлено термическим травлением с участием следов окислителя. Этот диапазон согласуется с данными работы [6], согласно которому в нашем случае, когда парциальное давление $\mathrm{O}_{2}$ составляет $2 \cdot 10^{-6}$ атм $\left(1.52 \cdot 10^{-3}\right.$ мм рт.ст.), температура, выше которой поверхность кремния остается неокисленной, т.е. преобладают реакции с образованием быстро улетающего $\mathrm{SiO}$, равна $1060^{\circ} \mathrm{C}$. О травлении в низкотемпературном диапазоне свидетельствуют и глубокие извилистые каналы и язвы на стенках пор, которые хорошо видны при большем увеличении (рис. 2,a). Каналы появляются, когда стенки пор становятся нулевой толщины и соединяются с соседями. Они проникают на глубину от одной трети до половины полной высоты пор (см. рис. $1, T=1050^{\circ} \mathrm{C}$, левый столбец). При $1100^{\circ} \mathrm{C}$ большая часть образовавшегося $\mathrm{SiO}$ быстро улетает, за счет чего высота пор снижается еще сильнее. Вместо ваты образуются окисные шарики, которые можно видеть как на дне каналов (рис. 2, $b$ ), так и на поверхности (рис. 1, $T=1100^{\circ} \mathrm{C}$, центральный столбец). При $T>1150^{\circ} \mathrm{C}$

Таблица 2. Высота пористого слоя в образце SQ4-29 в зависимости от температуры отжига в течение 30 мин

\begin{tabular}{c|c}
\hline$T,{ }^{\circ} \mathrm{C}$ & $l$, мкм \\
\hline Исходный & 47 \\
1000 & 39 \\
1050 & 39 \\
1100 & 35 \\
1150 & 46 \\
1200 & 37
\end{tabular}

Таблица 3. Среднее значение плотности поверхностных отверстий $N$, их радиуса $R$, радиуса пор под коркой $r$ и высоты пористого слоя $l$ в образце $p$-Si-4

\begin{tabular}{c|c|c|c|c}
\hline$T,{ }^{\circ} \mathrm{C}$ & $N$, мкм $^{-2}$ & $R$, мкм & $r$, мкм & $l$, мкм \\
\hline Исходный & 0.193 & 0.628 & 0.81 & 35.5 \\
1100 & 0.243 & 0.587 & 0.82 & 33.0 \\
1125 & 0.081 & 0.999 & 1.16 & 25.7 \\
1150 & 0.076 & 0.900 & 1.20 & 33.0 \\
1175 & 0.066 & 0.827 & 1.32 & 29.2 \\
1200 & 0.044 & 0.850 & 1.70 & 34.2 \\
1225 & 0.038 & 0.998 & 1.76 & 28.0
\end{tabular}


$a$

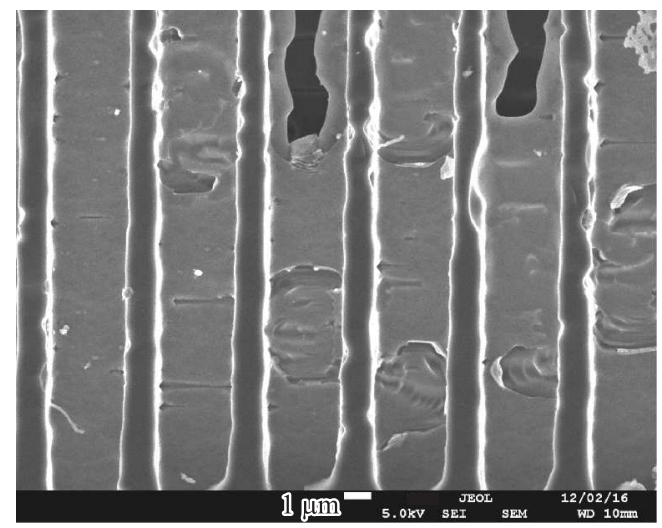

$b$

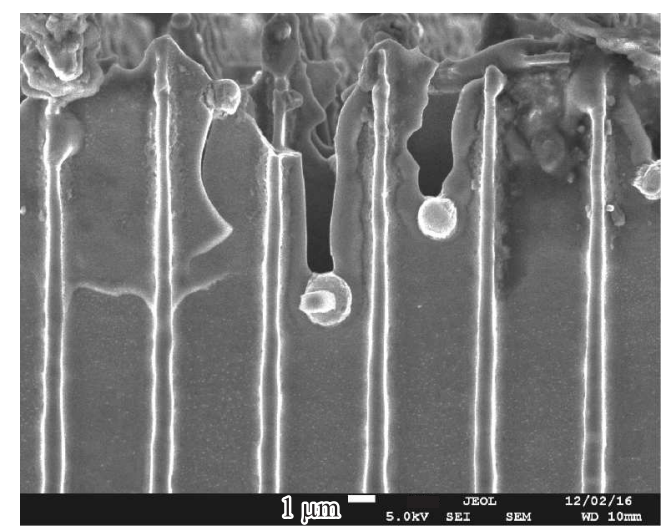

Рис. 2. Изъязвление стенок пор в образце SQ4-29 при $1050^{\circ} \mathrm{C}(a)$ и образование шариков окисла на дне образовавшихся каналов при $1100^{\circ} \mathrm{C}(b)$. Масштабный отрезок: 1 мкм.

снижение высоты $l$ обусловлено уже не травлением, а собственно усадкой пористого слоя, которая преобладает при высоких температурах.

Результаты изохронного отжига образца с неупорядоченными порами показаны на рис. 3. В табл. 3 суммируются результаты обработки SEM-изображений.

Эффект термического травления начинает проявляться при $1100^{\circ} \mathrm{C}$, он сопровождается образованием ромбовидных углублений в стенках пор (рис. 4), ограненных плоскостями (111). Это свидетельствует об анизотропном характере травления. Заметная реорганизация структуры за счет спекания начинается при $1125^{\circ} \mathrm{C}$. Но поскольку наблюдаемый эффект обусловлен двумя разными процессами: закрытием пор с образованием поверхностной корки и одновременным травлением, то на поверхности образца появляются характерные углубления в виде червяков, под которыми виден нижний этаж незакрывшихся пор. Преобразование при более высокой температуре есть результат конкуренции этих процессов, снижения роли термического травления и возрастания роли спекания за счет ускорения диффузионного массопереноса. С ростом температуры наблюдается монотонное уменьшение числа отверстий на единицу поверхности (рис. 5,a), что говорит о закрытии большинства пор. Однако видимая поверхностная пористость (рис. 5,b) при низких температурах увеличивается по сравнению с исходной, что свидетельствует о преобладании травления, а по мере роста $T$, когда превалирует спекание, поверхностная пористость снижается и становится меньше, чем исходная. Наименее дефектная корка образуется при $T=1200^{\circ} \mathrm{C}$. При $T>1200^{\circ} \mathrm{C}$ пористость опять несколько возрастает. Изменение среднего радиуса поверхностных отверстий с температурой показано на рис. 5, с. Эта зависимость также немонотонна: наблюдается резкий рост $R$ при $1125^{\circ} \mathrm{C}$, затем падение и вновь возрастание при $T>1175^{\circ} \mathrm{C}$. При наиболее высокой температуре $1225^{\circ} \mathrm{C}$ вновь сильно возрастает размер поверхностных отверстий, они коагулируют, и их форма становится вытянутой. Картина выглядит так, как будто идет травление корки и через расширившиеся отверстия опять видны внутренние поры. Высота пористого слоя изменяется немонотонно, будучи всегда меньше исходной, как это было и в предыдущем образце SQ4-29. Абсолютный минимум $l$ соответствует температуре $1125^{\circ} \mathrm{C}$, когда травление наиболее интенсивно.

Массоперенос при спекании может определяться разными механизмами [7], среди которых внутри пористого слоя определяющими являются объемная и поверхностная диффузия. Изменение размера внутренних пор $r$ определяется диффузионной длиной $L=\left(D_{\mathrm{Si}} \cdot t\right)^{1 / 2}$, где $D_{\mathrm{Si}}-$ коэффициент диффузии атомов кремния. Таким образом, $D_{\mathrm{Si}} \sim\left(r^{2}-r_{0}^{2}\right)$, где $r_{0}-$ начальное значение среднего радиуса цилиндрических пор. Как известно, температурная зависимость коэффициента диффузии носит активационный характер $D_{\mathrm{Si}}=D_{0} \cdot \exp \left(-E_{a} / k T\right)$, где $E_{a}-$ энергия активации. На рис. $5, d$ приведена зависимость величины, пропорциональной $D_{\mathrm{Si}}$, от обратного значения абсолютной температуры $\log \left(r^{2}-r_{0}^{2}\right)=f(1 / T)$. Полученная из нее величина $E_{a}=2.57$ эВ несколько превышает известные значения для энергии активации поверхностной диффузии 2.21 [8] и 2.3 эВ [9], но оказывается значительно ниже, чем энергия активации объемной самодиффузии в Si: 4.86 эВ $[10,11]$. Это говорит о смешанном механизме диффузии, обеспечивающей массоперенос при спекании.

\section{2. Изотермический отжиг}

Отжиг проводился на неупорядоченных структурах pSi-6 и pSi-7, изготовленных в одинаковом режиме. Выбор температуры был обусловлен желанием проследить за кинетикой отжига при наиболее низкой температуре, при которой уже становятся заметны изменения морфологии пор, и при максимальной температуре исследуемого диапазона. 


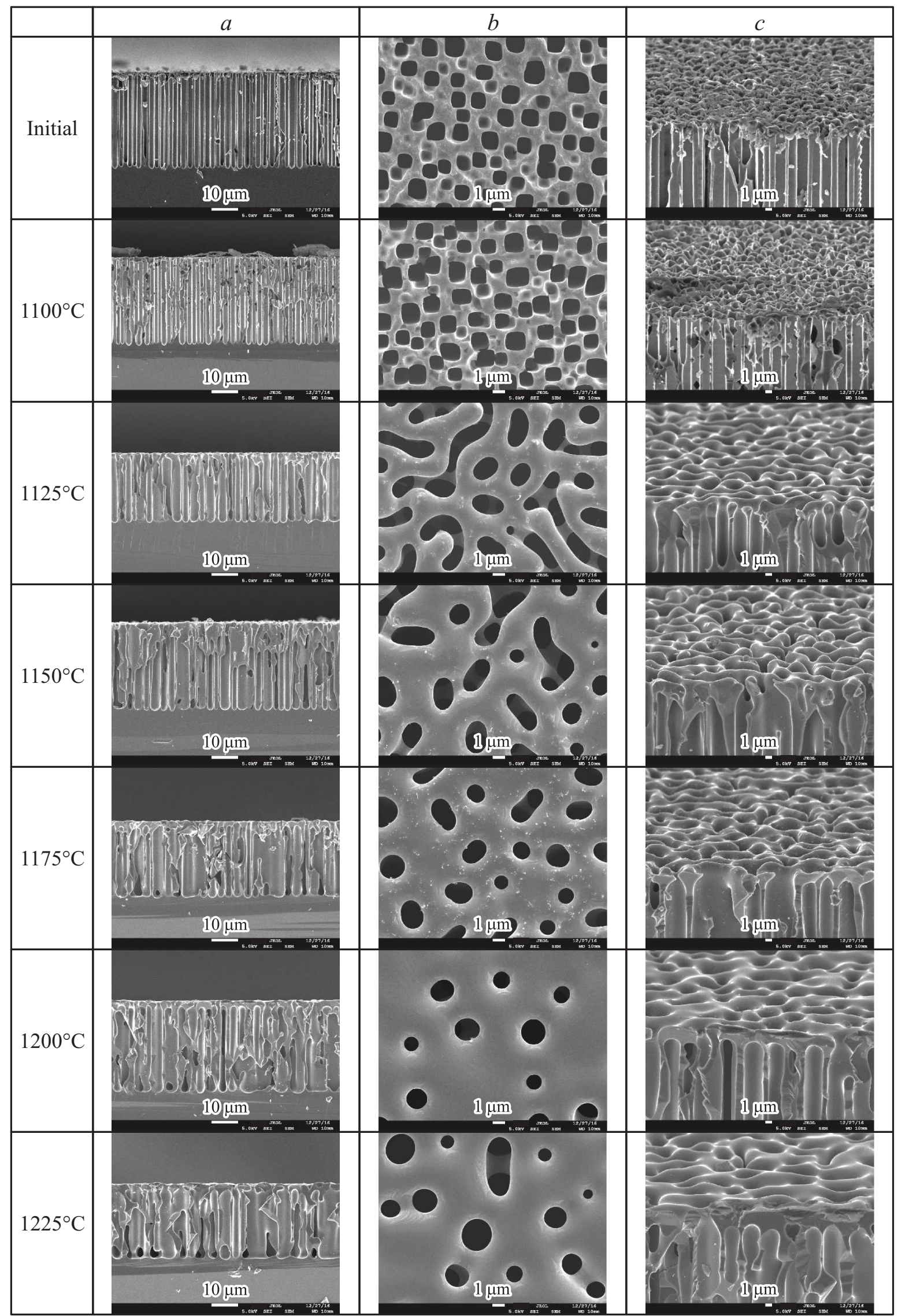

Рис. 3. Изохронный отжиг образца $p$-Si-4. Масштабный отрезок: $a-10$ мкм, $b, c-1$ мкм. 


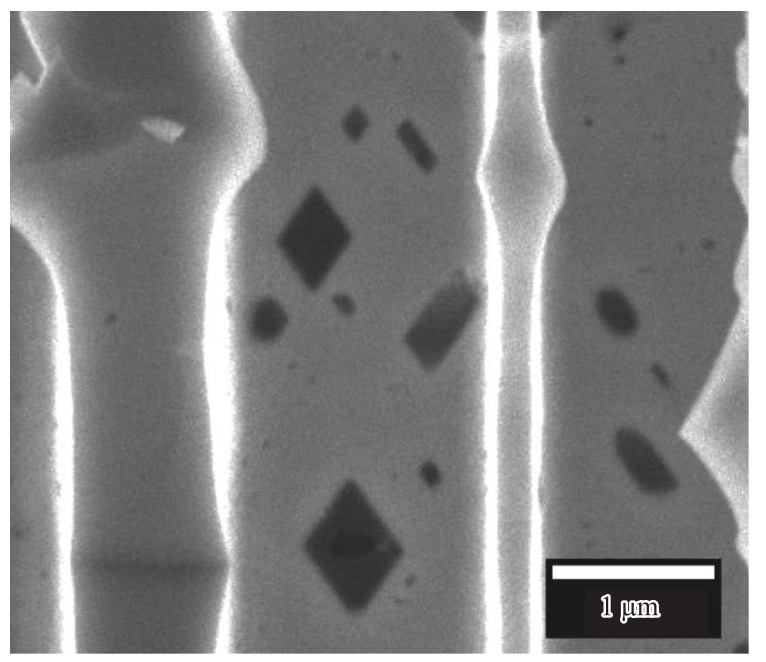

Рис. 4. Анизотропные ямки термического травления, появившиеся в стенах образца $p$-Si-4 после отжига при $1100^{\circ} \mathrm{C}$.

Рис. 6 и 7 позволяют сравнить изменения, происходящие в результате отжига при 1125 и $1225^{\circ} \mathrm{C}$ соответственно. Зарастание пор на поверхности и появление корки при $1125^{\circ} \mathrm{C}$ становится заметным только после отжига в течение 60 мин, а при $1225^{\circ} \mathrm{C}$ регистрируется уже через 12.5 мин, т.е. за минимальное время отжига в проведенном эксперименте. Видно, что по мере увеличения времени отжига отверстия в корке укрупняются. На рис. 8 приведены зависимости среднего радиуса поверхностных отверстий $R$ от времени для обеих температур изотермического отжига. Эти зависимости аппроксимируются прямыми с практически одинаковым наклоном, т.е. скорость изменения диаметра $v$ не зависит от температуры: при $T=1125^{\circ} \mathrm{C} v=2.3 \mathrm{Hм} /$ мин, при $T=1225^{\circ} \mathrm{C} v=2.4 \mathrm{Hм} /$ мин. Такое странное поведение никак нельзя объяснить диффузионными процессами массопереноса и следует предположить, что они определяются другим механизмом. Реакция, по-видимому, протекает по периметру отверстия и приводит к его разрастанию. Такой процесс превращения $\mathrm{SiO}_{2}$ в $\mathrm{SiO}$ при взаимодействии с $\mathrm{Si}$ наблюдался авторами $[12,13]$. Но реакции, приводящие к образованию $\mathrm{SiO}$, также должны зависеть от температуры. Поэтому нам представляется, что процесс лимитируется каким-то другим механизмом, независящим от температуры, например скоростью поступления окислителя.

Из рис. 7 видно, что под коркой внутри пористого слоя средний радиус $r$ цилиндрических пор возрастает, их верхние и нижние концы приобретают сферическую
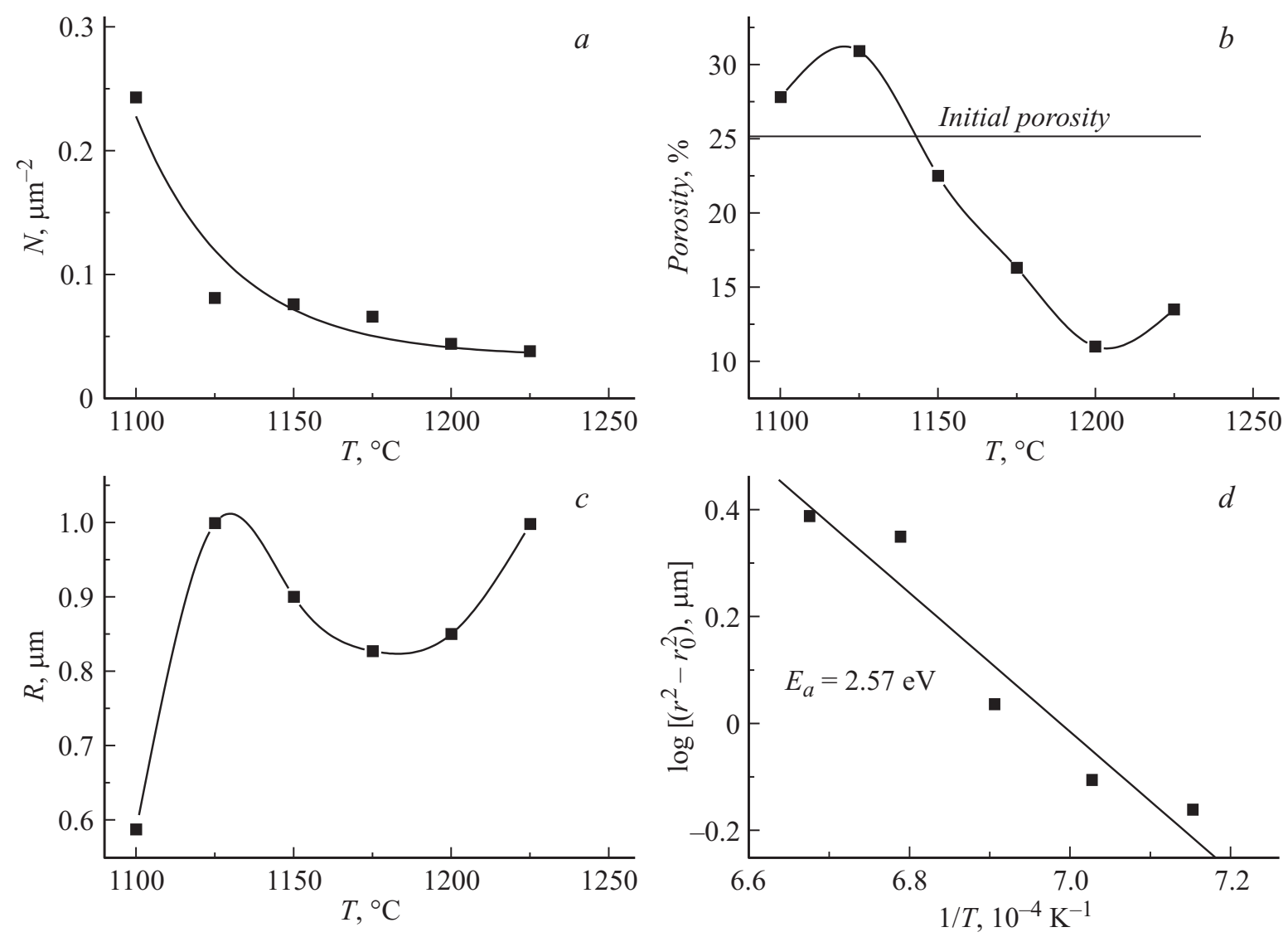

Рис. 5. Влияние изохронного отжига на структуру пористого слоя в образце $p$-Si-4: $a$ - температурная зависимость плотности поверхностных отверстий, $b-$ поверхностной пористости, $c-$ среднего радиуса отверстий на поверхности и $d-$ изменение квадрата радиуса внутренних пор под коркой от обратной температуры в полулогарифмическом масштабе. 


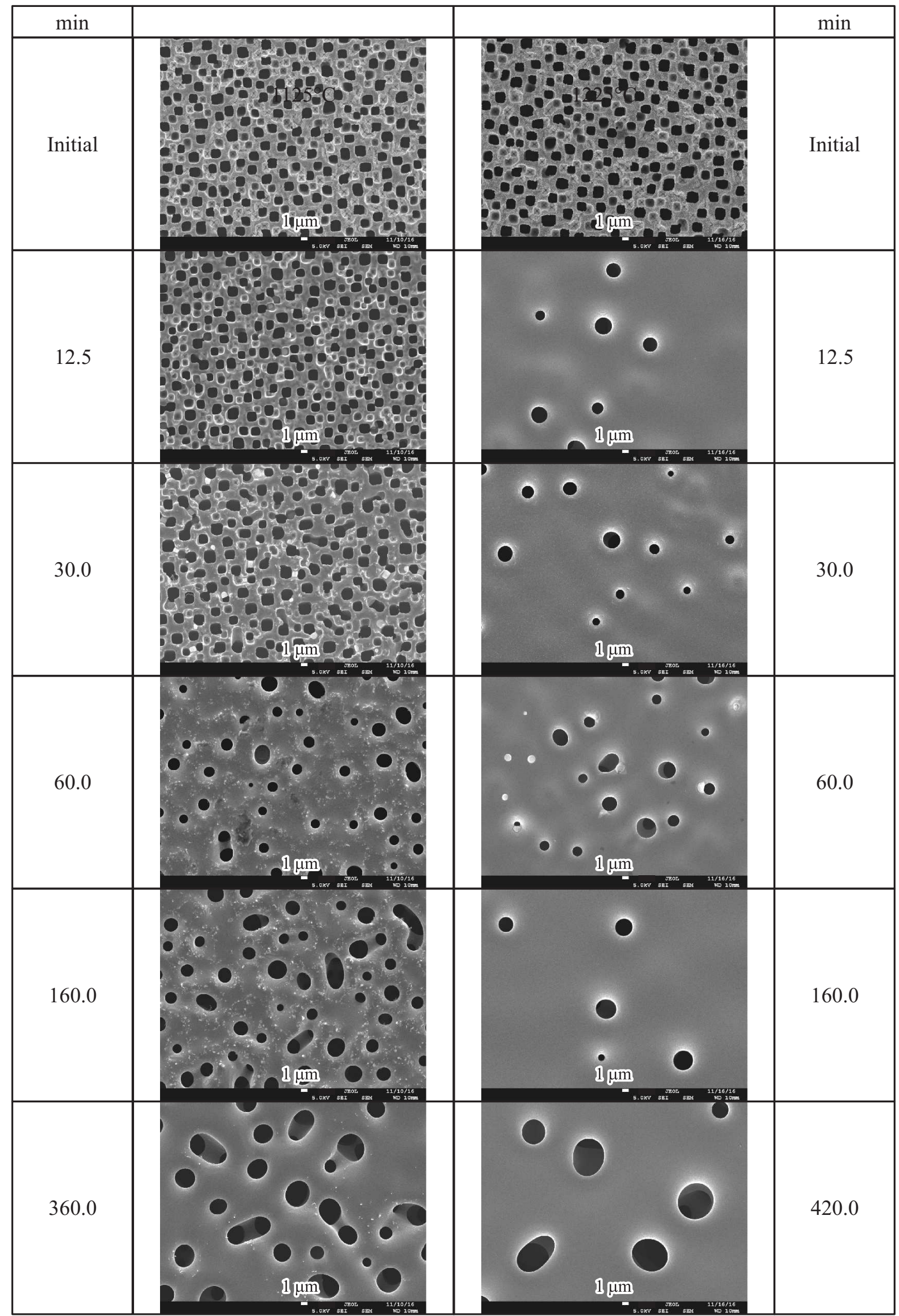

Рис. 6. Изотермический отжиг образцов $p$-Si-6 и p-Si-7, вид сверху. Масштабный отрезок: 1 мкм. 


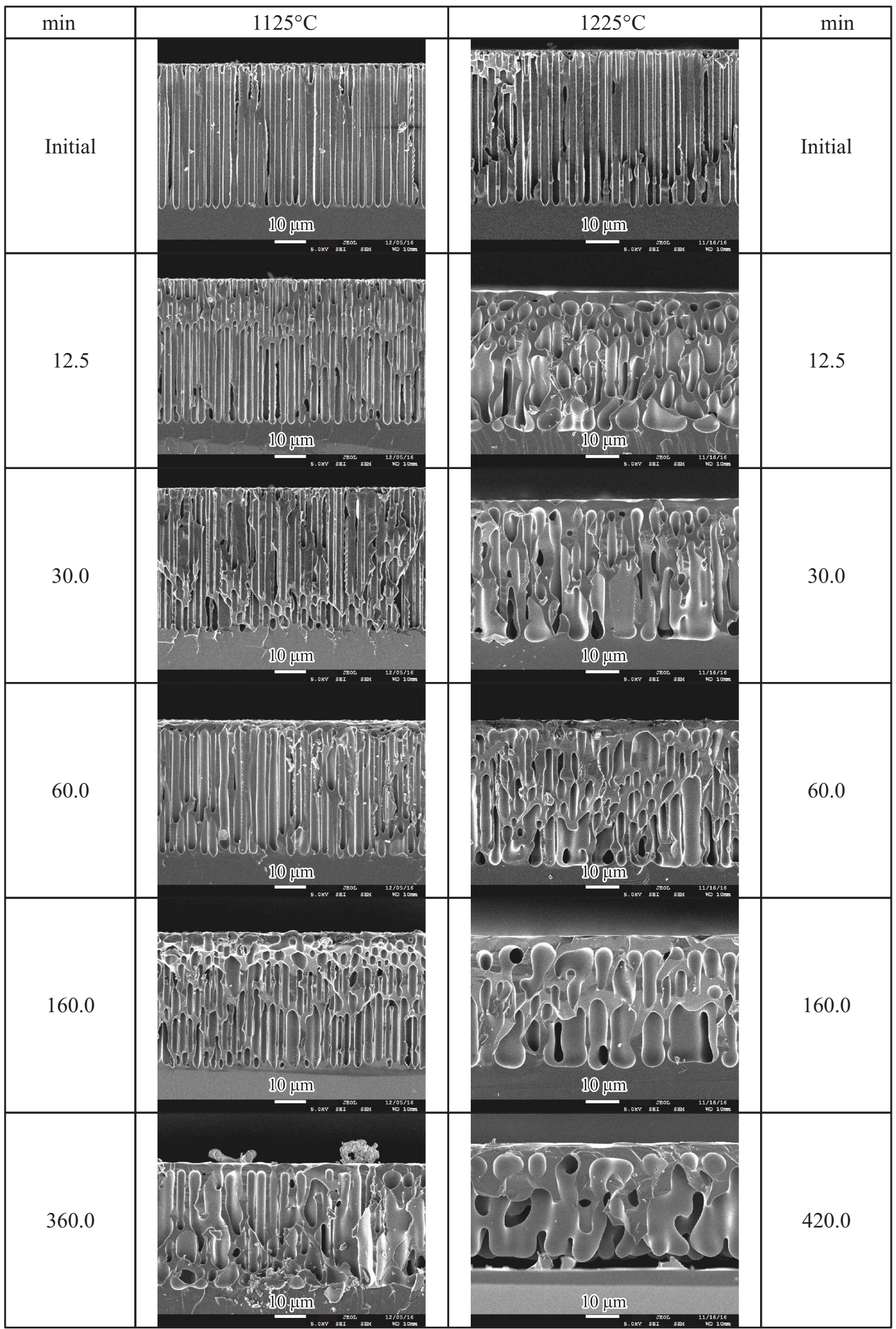

Рис. 7. Изотермический отжиг образцов $p$-Si-6 и p-Si-7, вид сверху. Масштабный отрезок: 10 мкм. 


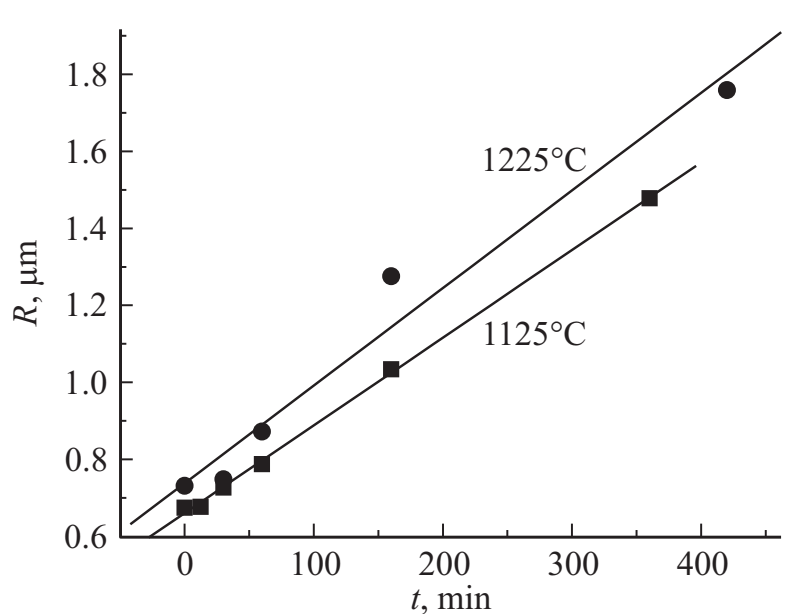

Рис. 8. Зависимость среднего радиуса поверхностных отверстий от времени отжига при температурах 1125 и $1225^{\circ} \mathrm{C}$.

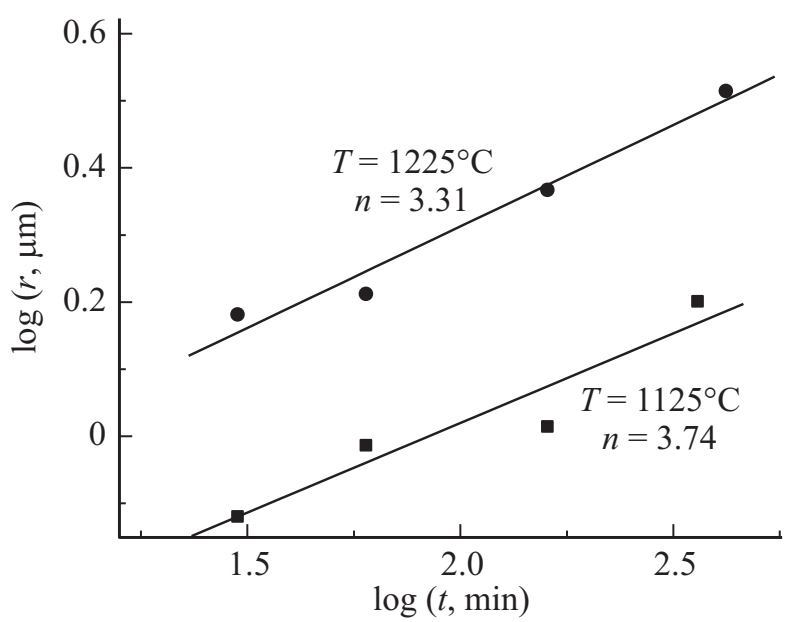

Рис. 9. Изменение радиуса пор внутри пористого слоя в зависимости от времени отжига при $T=1125$ и $1225^{\circ} \mathrm{C}$.

форму, а общая высота пористого слоя уменьшается. Особенно эффективно увеличение размера пор и усадка протекают при $T=1225^{\circ} \mathrm{C}$. Интересно, что через 420 мин происходит не только практически полное исчезновение цилиндрических пор, но и образование сплошной полости, отделяющей пористый слой от подложки. Известно, что кинетика изменения размера отдельных пор описывается степенной зависимостью $r \sim t^{1 / n}$, где $n=4$ для механизма поверхностной диффузии и $n=3$ для объемной [14]. При этом по мере увеличения размера пор и температуры роль объемной диффузии возрастает в силу более высокой энергии активации коэффициента диффузии. В нашем случае стремление к минимальной поверхности приводит к возрастанию диаметра цилиндрических пор и уменьшению их высоты (процесс сфероидизации). На рис. 9 приведены зависимости от времени среднего радиуса пор в двойном логарифмическом масштабе. Из наклона аппроксимирующих их прямых определены значения $n=3.74$ для $T=1125^{\circ} \mathrm{C}$ и $n=3.31$ для $T=1225^{\circ} \mathrm{C}$. Отсюда можно заключить, что механизм массопереноса носит смешанный характер с увеличением доли объемного транспорта при высокой температуре. Авторы предшествующих работ [1,15-18] считали механизм диффузии преимущественно поверхностным.

Следует отметить, что ни в одном из проведенных нами экспериментов не удавалось достигнуть полного заращивания пор на поверхности, т.е. получить бездефектную корку, как при отжиге в чистом водороде $[1,19]$. Дефекты в корке представляют собой отверстия, которые происходят от незакрывшихся пор. Их присутствие свидетельствует о конкуренции механизмов собственно спекания, приводящего со временем к зарастанию пор на поверхности, и растравливания, приводящего к увеличению размера отверстий.

\section{4. Заключение}

Проведенные эксперименты показали, что спекание макропористого кремния в атмосфере аргона высокой чистоты или аргона с небольшой добавкой водорода имеет особенности, обусловленные следами окислителя в газовой среде. Присутствие следов окислителя является причиной термического травления через образование газообразного $\mathrm{SiO}$. Конкуренция процессов травления и диффузионного массопереноса приводит к тому, что при низких температурах на поверхности образуется корка с большим количеством дефектов и пористостью, превосходящей пористость исходной структуры. Эффекты травления менее выражены при высоких температурах, когда массоперенос происходит быстрее. Температурная зависимость и кинетика изменения размеров внутренних пор свидетельствуют о том, что транспорт атомов кремния при спекании происходит за счет поверхностной и объемной диффузии, с большей долей поверхностного механизма.

Работа выполнена при финансовой поддержке РФФИ (грант № 15-08-02805), с использованием оборудования центра коллективного пользования „Материаловедение и диагностика в передовых технологиях“.

\section{Список литературы}

[1] V. Depauw, I. Gordon, G. Beaucarne, J. Poortmans, R. Mertens, J.-P. Celis. J. Appl. Phys., 106, 033516 (2009).

[2] V. Depauw, O. Richard, H. Bender, I. Gordon, G. Beaucarne, J. Poortmans, R. Mertens, J.-P. Celis. Thin Sol. Films, 516, 6934 (2008).

[3] Н.Е. Преображенский, Е.В. Астрова, С.И. Павлов, В.Б. Воронков, А.М. Румянцев, В.В. Жданов. ФТП, 51, 79 (2017).

[4] Е.В. Астрова, Н.Е. Преображенский, С.И. Павлов, В.Б. Воронков. ФТП, 51, 1202 (2017).

[5] https://imagej.nih.gov/ij/docs/intro.html Image J. Image Processing and Analysis in Java: (02.05.2017).

[6] F.W. Smith, G. Ghidini. J. Electrochem. Soc.: Sol. St. Sci. Technol., 129, 1300 (1982). 
[7] Izabela Kuzma-Filipek. Sintering of Porous Silicon. In: Handbook of Porous Silicon, ed. L. Canham (Springer International Publishing, Switzerland, 2014) p. 599.

[8] К.Л. Гаврилюк, Ю.С. Кагановский, В.Г. Лифшиц. Кристаллография, 26, 561 (1981).

[9] M.E. Keeffe, C.C. Umbach, J.M. Blakely. J. Phys. Chem. Solids, 55, 965 (1994).

[10] Б.И. Болтакс. Диффузия и точечные дефекты в полупроводниках (Л., Наука, 1972).

[11] Основы технологии кремниевых интегральных схем. Окисление, дифбузия, эпитаксия, под ред. Р. Бургера, Р. Донована. (М., Мир, 1969) с. 206.

[12] M. Liehr, J.E. Lewis, G.W. Rubloff. J. Vac. Sci. Technol. A, 5, 1559 (1987).

[13] G.W. Rubloff. J. Vac. Sci. Technol. A, 8, 1857 (1990).

[14] Я.Е. Гегузин. Физика спекания. 2-е изд. (М., Наука, 1984).

[15] T. Sato, K. Mitsutake, I. Mizushima, S. Taniguchi, Y. Tsunashima. Jpn. J. Appl. Phys., 39, pt. 1, 5033 (2000).

[16] G. Müller, M. Nerding, N. Ott, H.P. Strunk, R. Brendel. Phys. Status Solidi A, 197, 93 (2003).

[17] K. Sudoh, H. Iwasaki, R. Hiruta, H. Kuribayashi, R. Shimizu. J. Appl. Phys., 105, 083536 (2009).

[18] H. Kuribayashi, R. Hiruta, R. Shimizu, K. Sudoh, H. Iwasaki. Jap. J. Appl. Phys., 43, L 468 (2004).

[19] V. Depauw, I. Gordon, G. Beaucarne, J. Poortmans, R. Mertens, J.-P. Celis. Mater. Sci. Eng. B, 159-160, 286 (2009).

Редактор Г.А. Оганесян

\section{Characteristic properties of macroporous silicon sintering in argon atmosphere}

\section{E.V. Astrova, N.E. Preobrazhenskiy, S.I. Pavlov, V.B. Voronkov}

loffe Institute, 194021 St. Petersburg, Russia

Abstract Temperature and time dependences of macroporous silicon annealed in $\mathrm{Ar}$ or $\mathrm{Ar}+3 \% \mathrm{H}_{2}$ has been studied. We found contribution of different mechanisms which determine this process. Special features of macroporous silicon annealing were investigated by means of isochronous and isothermal sintering on samples with ordered and random macropores in the temperature range $1000-1225^{\circ} \mathrm{C}$. It has been found, that sintering of macroporous silicon at atmospheric pressure in inert gas flow containing $2 \cdot 10^{-4} \% \mathrm{O}_{2}$ strongly depends on thermal etching. It competes with processes of the material transport which are relevant for sintering and blocks formation of a defect-free surface crust. The cause of etching is generation of gaseous silicon monoxide, which is removed with gas flow. The etching effect dominates in low temperature range and does not depend on $\mathrm{H}_{2}$ addition. We found the activation energy of silicon diffusion coefficient $E_{a}=2.57 \mathrm{eV}$ and index in the power low of the average pore radius on the annealing duration $r \sim t^{1 / n} n=3.74$ for $T=1125^{\circ} \mathrm{C}$ and $n=3.31$ for $T=1225^{\circ} \mathrm{C}$. These values indicate a mixed mechanism of material transport by surface and volume diffusion of $\mathrm{Si}$ atoms. 